\title{
Towards A Healthy Diet by the Hand of Phileas Fogg and Passepartout
}

\author{
Beatriz Mederer-Hengstl Aurora Bueno-Cavanillas Pilar Núñez-Delgado \\ University of Granada, Spain
}

\begin{abstract}
The importance of a healthy diet is unquestionable nowadays. Scientific evidence shows increased risk of obesity, diabetes as well as cardiovascular diseases attributable to an inadequate diet, both in developed and developing countries. At the same time, the dietary patterns of our population are increasingly based on nutrient-poor foods with high levels of fat, gradually moving away from a healthy eating pattern. Achieving healthy habits in our fast-food society might not be an easy task. Research undertaken in school contexts after interventions through educational programmes indicates more or less significant results in the short term. The problem lies in how to instil understanding and awareness about the importance of dietary changes and ensure the acquisition of good eating habits. Schools can and must provide a variety of opportunities to allow constructive dialogues and an effective consciousness. The aim of this paper is to reveal how the reading of a classic novel in a fourth-grade class might become a link in the chain which enables the promotion of health-consciousness about food in children, simultaneously with the implementation of curricular contents in both Spanish and English languages. This task provoked an enriching and reflective dialogue whilst creating a positive and appropriate climate for the development of a conscious attitude and the subsequent construction of healthy behaviours. The discussion with 9-10-year-old children regarding messages derived after the reading of children literature, promotes changes in the perception of healthy lifestyles.
\end{abstract}

Keywords: eating habits; health education; food consciousness; school context; classic literature. 


\section{Introduction}

The content in the school curriculum is quite dense, and its full implementation requires well-structured and defined programming and planning which allows us to make the most of available material resources, space and time. The reading of Jules Verne's novel, Around the World in Eighty Days, far from being only an approach to classic literature or a mere reading comprehensive task, provides us with a real didactic experience with several objectives. The choice of this work was largely motivated by another aim, that of learning about different food cultures in the countries visited by the main characters and as a vehicle to promote a dialogue on healthy eating habits, as well as an analysis of the main ingredients and traditional methods of preparation in those countries.

A substantial amount of literature has emerged showing the need for public health programs. In the past, leisure activities for children used to involve active play, but today children are engaged in quite sedentary activities such as watching television or playing video games (Popkin, 2001). As noted by Caballero, clear evidence of the alarming trend in obesity rates had already been provided by the regular, nationally representative surveys carried out from the 1960s onwards (Caballero, 2007). According to the World Health Organization (WHO), there were about 1.6 billion overweight adults aged 15 years and over and at least 400 million adults were obese worldwide in 2005. Even in less developed countries obesity has been identified as a major cause of disability and premature deaths. Given that obesity increases the risk of chronic non-communicable diseases, appropriate strategies need to be adopted, otherwise this new pandemic will continue to spread for the foreseeable future in both developed and developing countries (Prentice, 2006).

In order to address childhood obesity, multiple factors must be considered. There are not only biological and parental but also societal influences. Food is a heavily promoted commercial product, and children are targets (Kosti \& Panagiotakos, 2006).

\subsection{Health education interventions through educational programmes.}

As reported by Bartlett (1981), traditional school health education programmes have shown their effectiveness in increasing knowledge, being effective in improving attitudes but generally ineffective in changing health habits. More recently, McNeil and Flynn (2006) carried out a survey showing that current programmes have led to improvement in the short term. In line with this research, intervention carried out in schools from different European countries (Velde et al., 2008) revealed significant effects in the short term, although a year later, only in Norway was a significant impact observed. More specifically, Duddley, Cotton and Peralta (2015) performed a systematic review of school-based teaching interventions addressing to the promotion of healthy eating habits in primary schools. Their focus was centred on four healthy eating objectives: reducing energy intake or food consumption; increasing fruit and vegetable consumption; reducing sugar consumption and increasing nutritional knowledge. According to this study, the dominant teaching strategies were implemented within the curricula or crosscurricula activities, and proved to be very effective, showing statistically significant outcomes in the short term. 
On the other hand, most lifestyle interventions only address the promotion of healthy habits while children are at school, while there is strong evidence that children are more likely to be inactive and consume unhealthy food when they are at home (Duncan et al., 2011). Childhood and adolescence are crucial periods to form and consolidate healthy eating habits and other lifestyle aspects that will continue into adulthood, having an impact on risk factors for obesity and other illnesses (Bartrina, 2005). Nevertheless, Swartz argues that children are not going to learn what is healthy and that their learning will not lead them to an intelligent choice of what to eat or not, if they just memorize all this knowledge. "We will succeed by integrating an effective thinking into the content" ("technique of infusion") (Swartz et al., 2013).

\subsection{The importance of classic literature in the classroom}

The current activities in which children spend their leisure time affect not only their lifestyle by making it more sedentary but also their relationship with reading. Reading is related to school while television and video games mean leisure time (Dueñas \& Tabernero, 2013). Appropriate environments need to be developed to encourage children to keep on reading.

These sociological and technological changes are also asking for a new approach in the learning process which promotes the access to the content as well as the enjoyment of works and their authors and the literature in itself (Jiménez \& Romero, 2015; Abril, 2014; Mendoza, 2012; Núñez \& Alonso, 2015; Arbonés et al., 2015). According to Sánchez Corral (1995, in Bermúdez \& Núñez, 2012), the treatment of reading has to be interdisciplinary, and this approach must not only be an end in itself, but also an instrument in the development of language skills. For many authors (Arbonés et al., 2015; Núñez \& Alonso, 2015 among others) children's and young adults' literature is a main resource for teaching both literature and language.

The role of classics in education has been emphasized by many authors. Strong arguments are used to support the use of classics in the classroom. According to Sotomayor, for being writing and speaking models; because they represent cultural identities and for the sake of the balance between tradition and innovation in education (Sotomayor, 2013). Calvino defined classics as books that have never finished saying what they have to say (1991, in Sotomayor, 2013). Despite the merits of the classics, research has found that there is a current lack of multicultural literature including classics in the existing canon for children (Pirofksi (2001). Molina \& Cubillas argue that reading texts are selected according to the teacher's reading preferences; by the book market or integrated in the school curriculum (in Bermúdez \& Núñez, 2012).

Supporting the value of classics for interdisciplinary teaching, Verne's classic Around the World in Eighty Days had already been chosen for two other experiences. Carried out with college students, the aim of one of these experiences was to illustrate the physical and cultural diversity of the Earth's surface, helping teach the National Geography Standards (Akmal \& Ayre-Svingen, 2010). Later on, this piece of work was selected and adapted for children from $3^{\text {rd }}$ grade and used in order to define a model of critical thinking with the aim to provide a suitable sequence of the skills required for critical thinking (Gelerstein et al., 2016). The use of 


\section{5-17 March 2019 Berlin, Germany}

adapted versions makes original text more accessible for children and allows a first approach to the traditional text (Sotomayor, 2013).

\section{The experience in the classroom}

\section{Introduction}

This experience was set in a fourth-grade classroom in La Asunción Primary and Secondary School in Granada (Spain) aiming to achieve several objectives, both cross-curricular and curricular: to improve their reading fluency as well as their reading comprehension both in English and Spanish; to improve their writing and speaking skills in Spanish; to promote L2 speaking; to develop critical thinking; to expand their knowledge of Verne's classic novel as well as to acquire an appreciation for literature

\section{Methods}

The experience included several tasks. In order to implement them, students were placed into seven groups of four members each, and each group were assigned a different task. Groups were rotating all around the lessons so that all of them had chance to undertake all suggested tasks. Most of the them were performed using the cooperative learning technique known as shared reading.

The experience took place according to both planning showed below. Table 1 indicates the task performed by each group during the first lesson; on the following days groups kept on with the next task according to this distribution.

Table 1: Tasks distribution

\begin{tabular}{|c|c|c|c|}
\hline GROUPS & TASKS & LANGUAGE & MATERIAL \\
\hline No. 1 & $\begin{array}{l}1 . \\
\text { Reading }\end{array}$ & Spanish & $\begin{array}{l}\text { La vuelta al mundo en } 80 \text { días. } \\
(2004)\end{array}$ \\
\hline No. 2 & 2. Reading & Spanish & $\begin{array}{l}\text { La vuelta al mundo en } 80 \text { días } \\
\text { (2018) }\end{array}$ \\
\hline No. 3 & 3. Reading & Spanish & $\begin{array}{l}\text { La vuelta al mundo en } 80 \text { días. } \\
\text { (1987) }\end{array}$ \\
\hline No. 4 & 4. Reading & English & $\begin{array}{l}\text { Around the World in Eighty Days. } \\
\text { (2010) }\end{array}$ \\
\hline No. 5 & 5. Places of interest & $\begin{array}{l}\text { Spanish } \\
\text { English }\end{array}$ & Computer \\
\hline No. 6 & 6. Food Culture & $\begin{array}{l}\text { Spanish } \\
\text { English }\end{array}$ & Computer \\
\hline No. 7 & $\begin{array}{r}\text { 7. Designing and } \\
\text { drawing }\end{array}$ & $\begin{array}{l}\text { Spanish } \\
\text { English }\end{array}$ & Drawing tools \\
\hline
\end{tabular}


The tasks were distributed in concordance with the countries visited by the characters in the novel. This distribution encouraged them to search for information about the places of historical interest as well as about the different food cultures as it is shown in table 2.

Table 2: Distribution according to the stations (places of interest) and food culture.

\begin{tabular}{|c|c|c|c|}
\hline PLANNING & GROUPING & STATIONS & FOOD CULTURE \\
\hline $1^{\text {st }}$ Lesson & 7 groups of 4 pupils & From London to Paris & French cuisine \\
\hline $2^{\text {nd }}$ Lesson & 7 groups of 4 pupils & From Paris to Brindisi & Italian cuisine \\
\hline $3^{\text {rd }}$ Lesson & 7 groups of 4 pupils & From Brindisi to Suez & Middle Eastern cuisine \\
\hline $4^{\text {th }}$ Lesson & 7 groups of 4 pupils & From Suez to Bombay & Indian cuisine \\
\hline $5^{\text {th }}$ Lesson & 7 groups of 4 pupils & $\begin{array}{c}\text { From Bombay } \\
\text { to Singapore and to } \\
\text { Yokohama }\end{array}$ & $\begin{array}{c}\text { Chinese \& Japanese } \\
\text { cuisine }\end{array}$ \\
\hline $6^{\text {th }}$ Lesson & 7 groups of 4 pupils & $\begin{array}{l}\text { From Yokohama to } \\
\text { San Francisco }\end{array}$ & Mexican cuisine \\
\hline $7^{\text {th }}$ Lesson & 7 groups of 4 pupils & $\begin{array}{c}\text { From San Francisco to } \\
\text { New York }\end{array}$ & American cuisine \\
\hline $8^{\text {th }}$ Lesson & Group discussion & "Back to School" & Mediterranean cuisine \\
\hline
\end{tabular}

Each lesson was structured according to the following plan.

Task 1

The first task consisted on reading some chapters of the novel using the Spanish adapted version for 8-10-years-old children. The number of chapters to be read in each lesson was related to the plan shown in the table above, so that during the first lesson, e.g. children started reading the book and till Mr. Fogg and Passepartout arrive in Paris, and so on during the next lessons.

Task 2

Similar to the previous task but using the chosen version for 10-12-years-old children.

Task 3

In this case, students used the original Spanish version.

All this reading tasks were performed according to the Shared Reading Technique. In turns three of them read in silent and one aloud, making the most in reading enthusiastically and with expression, trying to be fluent. After having read some pages, another student in the group retold the story in their own words; the other members had chance to add, change or even comment some information ensuring the fully and properly comprehension of the story. They could also make predictions about what they thought was about to happen.

Task 4 
The group in charge of this task had to read the English adapted version while guided and supported by a teacher, who explicitly modelled the skills, including inflection, tone, fluence and pronunciation. Students were also asked brief questions to determine their comprehension level as well as to improve their L2 speaking skills.

\section{Task 5}

The group were encouraged to search for information about places of interest in the corresponding city, in order to present and explain their findings to all the class.

\section{Task 6}

The group had to search for information about the food culture in the country. As in the previous one, this task implied that students had to prepare a little speech in advance.

\section{Task 7}

To accomplish the task, children were allowed to choose, imagine and draw a character or a scene, taken into account the descriptions, setting and details given in the story.

Once all tasks have been concluded, a volunteer from the reading tasks retold the story aloud to the whole class allowing all students to follow the argument independently of the chapters assigned in their reading turns. Next, the teacher started a group discussion focussed on several aspects. The first one was supported by a compare and contrast graphic organizer which allowed an analysis of the differences between all three Spanish versions. Main purposes of this activity were to develop writing skills as sentence expanding, combining or even shortening, as well as to expand their vocabulary with new words and synonyms. Secondly, students in the fifth task presented the places of interest in the city; they were able to use de digital board for showing some photos of the chosen ones while their explanation. In the same way, the next group was accountable for teaching their findings according to the food culture in the particular country. After some little time for reactions and comments, the lesson concluded by tracking the next station in the book and in a world map on the digital board.

The last lesson involved an analysis of all different food cultures addressed and the group discussion on healthy eating habits related to the final objective of this experience.

\section{Results}

Reading all three Spanish versions promoted undoubtedly their fluency, but the most significant improvement achieved was reflected in subsequent writing activities. Students grew in overall instructional writing level. They enhanced their written language performing more accurate and complex sentences using a higher amount and variety of conjunctions to combine them; giving more detailed information through the addition of adjectives or adverbs; modifying nouns or using synonyms.

Students became more engaged with literacy, acquiring an appreciation for literature and respect of classic. They also developed knowledge of the author and their work; some of them even started reading other titles e.g. A Journey to the Centre of the Earth or Twenty Thousand Leagues under the Sea. 
Thanks to the L2 reading task, students become more strategic in word identification and more automatic in word recognition. They improved in decoding, pronunciation and intonation what led them to a more fluent and comprehensive reading.

Furthermore, the speaking tasks entailed speeches related to places of interest and food cultures providing them with the, sometimes frightening chance to speak aloud in front of the class. They had to transmit clearly their thoughts or knowledge; change the voice and the tone to encourage the audience, giving an attention to their gestures, poses and eyes contact. A challenge which can only be managed with the practice.

To accomplish the final task, children were allowed to choose, imagine and draw a character or a scene, taken into account the descriptions, setting and details given in the story.

Moreover, and along the lines of Gelerstein's research, children had to put into practice a number of sub-skills (e.g. interpretation, analysis, evaluation, inference and explanation) throughout the whole experience (Gelerstein et al., 2016). Drawing task also contributed to develop creative thinking skills and. simultaneously, to motivate and engage children.

Additionally, students gained knowledge and interest about the world and different cultures. Some topics or comments arose during the discussion and allowed the introduction of some historical issues e.g., the fact that California was once Mexican; those who had watched the movie "The Mask of Zorro" were able to enrich their movie comprehension, feeling also excited about the fact of being competence to make these connections. They become also surprised when they acknowledged that their opinions and suggestions were valid and valuable.

As in the study performed by Donaldson \& Kuhlke (2009), students expanded their knowledge of geography and about the role of changing technology and how that affects the world.

\section{Discussion}

The aim of this experience was, in the fact, more address to the achievement of crosscurricular rather than curricular content. The final discussion during the last lesson under the guidance of the teacher, involved an analysis of the main basic ingredients in the different food cultures and their possible relevance in a balanced diet and according to the suggested food pyramid; traditional methods of preparation were also an issue to be addressed.

Among others, following question arise during the group discussion: why were particular foods or menus healthy? Why do people in a country eat so much from a specific food, e.g. meat? why, if it is so unhealthy? what happens when people eat too much unhealthy food? Why do people prefer some foods? Why do we eat so much sugar or sweets? Why don't we always eat healthy foods? Have you ever been to an Italian/Indian/Mexican/Chinese/Japanese restaurant? What did you like best? Do you like spicy food? Do you think it is healthy or 
unhealthy food and why? what kinds of oils do we know? Which one is the best and why? Why is Mediterranean food healthy? Do you feel proud of being from the country with the best diet? Why do you think we are changing our diet? Why do we eat fast food? What could we do to promote health habits?

Students were generally able to distinguish between healthy and unhealthy foods, knew the food pyramid as well as the value of the main nutrients, even though there was a contradiction between knowledge and habit. Most of them reported that they frequently ate unhealthy foods and that they enjoyed them, feeling sad about the foods they should try to avoid. On the contrary, they felt really satisficed knowing that there were healthy foods that they do like.

Students internalized the message about eating a healthy diet, however, in order to certainly instill this message in pursuance of a change in children's diet in the long term, more activities are to be undertaken. Evidence demonstrates the relevance of schools to expose children to healthy eating habits (Hesketh, 2005). Therefore, schools can and must provide clear and consistent messages about healthy habits.

\section{Conclusion}

The aim of this paper was to reveal how the implementation of an experience focussed on the enhancement of curricula content, in this specific case, developing of comprehensive, reading and speaking skills, can also target particular content in health education.

In the final analysis, children became more proficient in writing and reading abilities; they understood and demonstrated that reading is a meaning-seeking process and they grew in knowledge, interest, and attitudes toward reading, writing and literature. On the other hand, the discussion with 9-10-year-old children regarding messages derived after the reading of children literature, promotes changes in the perception of healthy lifestyles.

Summarizing, it can be said that the reading of a classic novel in a fourth-grade class enables the implementation of curricular contents in both Spanish and English languages simultaneously with the promotion of health-consciousness about food in children, thanks to an enriching and reflexive discussion whilst creating an appropriate climate for the development of a conscious attitude and the subsequent construction of healthy behaviours.

\section{Acknowledgment}

This experience is part of a project which involves a series of tasks focused on the same objective: the promotion of healthy habits on children throughout the reading of children's literature. 


\section{References}

[1] Abril, M. (2014): La educación literaria: experiencias de aprendizaje. Octaedro: Barcelona.

[2] Arbonés, C., Prats, E. and Sanahuja, E. (2015). Literatura 2.0 en el aula. Octaedro: Barcelona.

[3] Bartlett, E. E. (2011). The contribution of school health education to community health promotion: what can we reasonably expect? American Journal of Public Health. Available: https://ajph.aphapublications.org/doi/abs/10.2105/AJPH.71.12.1384

[4] Belashen, R., Rguibi, M (2006). Population health and Mediterranean diet in southern Mediterranean countries, Public Health Nutrition, vol. 9 (8A), pp.1130-1135.

[5] Bermúdez, M. y Núñez, P. (2012). Canon y educación literaria. Octaedro: Barcelona.

[6] Caballero, B. (2007). The Global Epidemic of Obesity: An Overview, Epidemiologic Reviews, vol. 29 (1), pp. 1-5.

[7] Calvino, I. (1991). Por qué leer a los clásicos. Tusquets: Barcelona

[8] Donaldson, D. and Kuhlke, O. (2009). Jules Verne's Around the World in Eighty Days: Helping Teach the National Geography Standards, Journal of Geography, 108 (2), pp.3946.

[9] Dudley, D., Cotton, W. and Peralta, L. (2015): Teaching approaches and strategies that promote healthy eating in primary school children: a systematic review and meta-analysis, International Journal of Behavioural Nutrition and Physical Activity, vol., 8 p.127. Available: http://www.ijbnpa.org/content/8/1/127.

[10]Dueñas, J. D. and Tabernero, R (2013), Los clásicos en el aula. Una propuesta: hipertextualidad y contexto histórico. Tejuelo, vol. 16, pp. 65-67.

[11]Duncan, S., McPhee, J. C., Schulter, P.J., Zinn, C., Smith, R. and Schofield, G. (2011). Efficacy of a compulsory homework programme for increasing physical activity and healthy eating in children: the healthy homework pilot study, International Journal of Behavioral Nutrition and Physical Activity,

[12]Gelerstein, D., Del Río, R., Nussbaum, M., Chiuminatto, P. and López, X. (2016). Designing and implementing a test for measuring critical thinking in primary school, Thinking Skills and Creativity, vol.20, pp. 40-49. 
[13]Hesketh, K., Waters, E., Green. J., Salmon, L., Williams, J. (2005). Healthy eating, activity and obesity prevention: a qualitative study of parent and child perceptions in Australia, Health Promotion International, vol. 20 (1), pp. 19-26.

[14]Jiménez, R., and Romero, M. F. (2015). Nuevas líneas de investigación e innovación en la educación literaria. Octaedro: Barcelona.

[15]Kosti, R. I. and Panagiotakos, D. (2006). The epidemic of obesity in children and adolescent in the world, Cent. Eur. J. Public Health, [Online] vol. 14 (4), pp. 151-159. Available: https://cejoh.szu.cz/pdfs/cjp/2006/04/01.pdf

[16]McNeil, D. and Flynn, M. (2006). Methods of defining best practice for population health approaches with obesity prevention as an example. Proceedings of Nutrition Society, vol 65 (4), pp. 403-411. Available: https://doi.org/10.1079/PNS2006520

[17]Mendoza, A. (2012): Leer hipertextos. Barcelona: Octaedro.

[18]Molina and Cubillas in Bermúdez, M. and Núñez (2012). Canon y educación literaria. Barcelona: Octaedro.

[19]Núñez, P. and Alonso, I. (2015). Innovación docente en didáctica de la lengua y la literatura: teoría e investigación. Octaedro: Barcelona.

[20]Pirofski, K. I. (2001). Multicultural Literature and the Children's Literary Canon. Available: http://www.edchange.org/multicultural/papers/literature.html.

[21]Popkin, B. M. (2001). The Nutrition Transition and Obesity in the Developing World, The Journal of Nutrition, vol. 131, pp. 871S-873S.

[22]Prentice, A. M. (2006). The emerging epidemic of obesity in developing countries, International Journal of Epidemiology, vol. 35 (1) pp. 93-99.

[23]Sánchez Corral, L. (1995). Literatura infantil y lenguaje literario. Paidós: Barcelona.

[24]Sotomayor, M.V. (2013).¿Qué hacemos con los clásicos? Algunas reflexiones para los futuros docentes. En Lenguaje y Textos. Revista de la Sociedad Española de Didáctica de la Lengua y la Literatura, vol. 38, pp. 29-37.

[25]Swartz, R., Costa, A., Beyer, B., Reagan, R. y Kallick, B. (2013). El aprendizaje basado en el pensamiento. Como desarrollar las competencias del siglo XXI. Biblioteca Innovación Educativa. 3rd Ed. S.M.

[26]Twain, M. (2018). La vuelta al mundo en 80 días. Clásicos a medida. Adapted by Ana Alonso. Anaya: Madrid 
[27]Velde, S., Brug, J., Wind, M., Hildonen, C., Bjelland, M., Pérez-Rodrigo, C., and Klepp, K. (2008). Effects of a comprehensive fruit- and vegetable-promoting school-based intervention in three European countries: The Pro Children Study. British Journal of Nutrition, 99 (4), 893-903.

[28]Verne, J (1987). Around the World in Eighty Days. Adapted, $1^{\text {st }}$ ed., 2002 Oxford University Press: Oxford.

[29]Verne, J. (1987): La vuelta al mundo en 80 días. Edicomunicación, S.A.: Barcelona

[30]Verne, J. (2017). La vuelta al mundo en 80 días. Adapted by Jesús Cos. RBA Molino: Barcelona.

[31]WHO. Diet, Nutrition and the Prevention of Chronic Diseases. Report of a Joint WHO/FAO Expert Consultation. WHO Technical Report Series 916. Geneva: World Health Organisation, 2003. 